\title{
Factors associated with parental reasons for "no-intent" to vaccinate female adolescents with human papillomavirus vaccine: National Immunization Survey - Teen 2008-2012
}

\author{
Vinay K. Cheruvu*, Madhav P. Bhatta and Lauren N. Drinkard
}

\begin{abstract}
Background: 1) To identify socio-demographic factors associated with parental "no-intent" for their 13-17 year old unvaccinated daughter to receive the human papillomavirus (HPV) vaccine series within the next twelve months, 2) to describe patterns in "no-intent" by socio-demographic factors, and 3) to identify socio-demographic factors associated with parental reasons for "no-intent".

Methods: Data from 2008-2012 National Immunization Survey - Teen (NIS - Teen) were examined in this study. Parents with "no-intent" to vaccinate their daughters were asked to identify reasons for their decision. All responses were categorized into five domains identified as barriers to receive the HPV vaccine series: 1) Safety and Effectiveness Concerns; 2) Systemic Barriers; 3) Vaccine Misinformation; 4) Lack of Knowledge about the Vaccine; and 5) Socio-cultural Barriers. Multivariable logistic regression models were performed to address the study objectives.

Results: Number of people in the household, household income, mother's age, education, health insurance, recommendation of a health care provider, and the survey year were significantly associated with parental "no-intent". Race/ethnicity, mother's education, marital status, recommendation of a health care provider, household income, age of the unvaccinated daughter, and the survey year, were significantly associated with one or more domains identified as barriers to receive the HPV vaccine.

Conclusions: This study identified sub-groups of parents across different socio-demographic factors with "no-intent" for their adolescent daughters to receive the HPV vaccine. Developing strategies that target educational tools towards the identified sub-groups of parents about the purpose, safety, and efficacy of the HPV vaccine, and HPV infection, may help increase HPV vaccine acceptance, initiation and completion rates.
\end{abstract}

Keywords: HPV vaccine, Unvaccinated female adolescents, Reasons for no-intent, National Immunization Survey - Teen

\section{Background}

In the United States (U.S.), human papillomavirus (HPV) is the most prevalent sexually transmitted infection (STI) with up to $24.5 \%$ HPV infection among females aged 14-19 years [1-3]. HPV types 6 and 11, cause $90 \%$ of genital warts and HPV types 16 and 18 , cause $70 \%$ of cervical cancers [4]. Oncogenic HPV also causes vulvar, vaginal, anal cancers [5, 6]. In 2012, there

\footnotetext{
* Correspondence: vcheruvu@kent.edu

Department of Biostatistics, Environmental Health Sciences, and

Epidemiology, College of Public Health, Kent State University, Hilltop Drive, 320 Lowry Hall, Kent 44242, OH, USA
}

were two highly efficacious HPV vaccines on the market licensed by The Food and Drug Administration (FDA); the bivalent vaccine (Ceravix) which provides protection against high-risk oncogenic HPV types 16 and 18 only, and the quadrivalent vaccine (Gardasil) which provides protection against types 16 and 18, as well as two low risk types 6 and 11 [7-9]. In 2014, the 9-valent (Gardasil 9) virus-like particle HPV vaccine was approved which has the potential to increase cervical cancer prevention from $70 \%$ to $90 \%$ [10, 11]. The Healthy People 2020 goal for HPV vaccine coverage among female adolescents aged $13-15$ years in the U.S. is $80 \%$ [12]. Among females 
aged 14-19 years, Markowtiz and colleagues reported a decline in the prevalence of vaccine preventable HPV infections from $11.5 \%$ in 2003-2006 (the pre-vaccine era) to $5.1 \%$ in $2007-2010$ (the post-vaccine era) [13]. Despite a significant increase in HPV vaccination coverage during 2007-2011, the increase in the percentage of unvaccinated girls with at least one missed opportunity for HPV vaccination from $20.8 \%$ to $84.0 \%$ is a major public health concern [14]. These numbers highlight the potential of the HPV vaccine, the importance of developing educational strategies for parents about the vaccine, and the need for targeting vaccination campaigns towards adolescents to reduce HPV infections and their sequelae, most notably genital warts and cervical cancer.

A considerable number of studies have focused on the factors associated with initiation and completion of the HPV vaccine series [15-30]. For example, two studies reported older age of adolescent females was associated with initiation and completion of HPV vaccination [22, 23]. Only recently, the research focus has shifted to understand the population of unvaccinated teens, factors associated with "intent", and parental reasons for "no-intent" for their daughters to receive the HPV vaccine [25-35]. However, such studies were limited in that they only reported the most common reasons cited by parents for "no-intent" to vaccinate their adolescents, while failing to identify the underlying socio-demographic characteristics of such parents. Parental attitudes and beliefs regarding vaccines in general and the HPV vaccine in particular, affect the likelihood that their children will receive vaccines [36]. It is particularly important that we identify these socio-demographic sub-groups and develop targeted strategies to improve acceptance and uptake of the HPV vaccine.

In a recent study among unvaccinated females aged 15-25 years, Liddon and colleagues described the correlates of the main reasons for foregoing vaccination in females [33]. However, to our knowledge, factors associated with various self-disclosed parental reasons for "no-intent" to vaccinate their daughters have not been studied in a nationally representative sample of unvaccinated female adolescents aged 13-17 years.

In this study, we used a sub-sample of unvaccinated females aged 13-17 years from the National Immunization Survey - Teen (NIS - Teen), 2008-2012, to address three specific objectives: 1) To identify socio-demographic factors associated with parental "no-intent" for their 13-17 year old unvaccinated daughter to receive the human papillomavirus (HPV) vaccine series in the next twelve months, 2) to describe patterns in "no-intent" by sociodemographic factors, and 3) to identify socio-demographic factors associated with parental reasons for "no-intent".

\section{Methods}

National Immunization Survey-Teen (NIS-Teen)

Data from 2008-2012 NIS-Teen surveys were used for the analyses [37]. The NIS-Teen survey is implemented annually by the National Center for Immunization and Respiratory Diseases and the National Center for Health Statistics of the Centers for Disease Control and Prevention. It represents a stratified national probability sample of households in the U.S. that include all 50 states, the District of Columbia, and the U.S. Virgin Islands. Details about methodology and weighting procedures, have been previously published [38]. All estimates were based on adolescents with adequate provider data. The observations from the U.S. Virgin Islands were excluded from all analyses. The final sample size was 23,722. This study was exempt from review by Kent State University's IRB because NIS - Teen data are publicly available and deidentified.

\section{No-intent to receive the HPV vaccine series}

Parent (or guardian) of a female adolescent with no history of HPV vaccination at the time of the interview was asked the question "how likely is it the teen will receive $H P V$ vaccinations in the next 12 months?". Of the five possible responses, parents who responded "very likely" or "somewhat likely" were considered as having "intent" and those who responded "not too likely", "not likely at all", or "not sure/do not know" were considered as having "no-intent" for their daughter to receive the HPV vaccine series within the next 12 months. The percentage of parents who responded "not sure/do not know" was very small $(<3 \%)$. Parents with "no-intent" were then asked the question, "What is the main reason [your teen] will not receive HPV shots in the next 12 months? " Parents were allowed to report one or more reasons from a list which $\mathrm{CDC}$ created. For the present analyses, we created the following five domains for the reasons parents reported: i) Safety and Effectiveness Concerns, ii) Systemic Barriers, iii) Vaccine Misinformation, iv) Lack of Knowledge about the Vaccine, and v) Sociocultural Barriers. Table 1 shows the questions that went into each domain created based on qualitative groupings. Each domain is treated as a binary outcome in our analyses: "Yes" if a parent reported at least one of the reasons and "No" if no reason was reported in the corresponding domains.

\section{Statistical analysis}

Of the 23,722 unvaccinated females (2008: $n=5,126$; 2009: $n=4,901 ; 2010: n=4,614 ; 2011: n=5,231$; and 2012: $n=3,850), 21,467$ had information on all the covariates of interest. Of these, parents of 12,716 females were in the "no-intent" group, of which 12,274 of them reported at least one reason for their decision. 
Table 1 Reasons for no-intent to receive human papillomavirus vaccine (HPV) series among unvaccinated female adolescents aged 13-17 years, National Immunization Survey - Teen, 2008-2012

\begin{tabular}{|c|c|c|}
\hline Domain & Reason \# & $\begin{array}{l}\text { Main reason teen will not receive } \\
\text { HPV shots in the next } 12 \text { months }\end{array}$ \\
\hline \multirow{3}{*}{$\begin{array}{l}\text { Safety and } \\
\text { Effectiveness } \\
\text { Concerns }\end{array}$} & HPVI_REAS_11 & Safety Concern/Side Effects \\
\hline & HPVI_REAS_12 & Effectiveness Concern \\
\hline & HPVI_REAS_21 & More info/New Vaccine \\
\hline \multirow[t]{6}{*}{ Systemic Barriers } & HPVI_REAS_1 & Not Recommended \\
\hline & HPVI_REAS_10 & Costs \\
\hline & HPVI_REAS_23 & Not Available \\
\hline & HPVI_REAS_24 & Not a School Requirement \\
\hline & HPVI_REAS_26 & No OB/GYN \\
\hline & HPVI_REAS_28 & $\begin{array}{l}\text { No Doctor or Doctor's Visit Not } \\
\text { Scheduled }\end{array}$ \\
\hline \multirow{4}{*}{$\begin{array}{l}\text { Vaccine } \\
\text { Misinformation }\end{array}$} & HPVI_REAS_2 & Not Needed or Not Necessary \\
\hline & HPVI_REAS_5 & Not Sexually Active \\
\hline & HPVI_REAS_6 & Not Appropriate Age \\
\hline & HPVI_REAS_25 & Increased Sexually Activity Concern \\
\hline $\begin{array}{l}\text { Lack of Knowledge } \\
\text { about the Vaccine }\end{array}$ & HPVI_REAS_3 & Lack of Knowledge \\
\hline \multirow{3}{*}{$\begin{array}{l}\text { Socio-cultural } \\
\text { reasons }\end{array}$} & HPVI_REAS_16 & Don't Believe in Immunizations \\
\hline & HPVI_REAS_17 & Family/Parental Decision \\
\hline & HPVI_REAS_19 & Religion/Orthodox \\
\hline
\end{tabular}

The unadjusted weighted prevalence estimates with 95\% confidence intervals (CIs) were computed to describe the socio-demographic characteristics of unvaccinated female adolescents. Univariate analyses were performed to test for associations between sociodemographic factors and parental "intent" vs. "no-intent" for their daughters to receive the HPV vaccine series within the next 12 months. Multivariable logistic regression analysis was performed to determine the factors associated with "no-intent". To describe how the socio-demographic factors associated with parental "no-intent" changed over time, we computed the unadjusted weighted prevalence estimates with 95\% CIs for each survey year. The sample size for these analyses was 21,467. To determine how the socio-demographic factors associated with parental reasons for "no-intent", we performed multivariable logistic regression analysis treating the five domains as binary outcomes (Yes/No) correspondingly. The sample size for these analyses was 12,274.

Sampling weights provided in the 2008-2012 NIS - Teen public use data were used to obtain population-based estimates. All analyses were performed using $\mathrm{SAS}^{\bullet}$ version 9.3 (Cary, NC, USA) survey procedures (PROC SURVEYFREQ, PROC SURVEYMEANS, PROC SURVEYLOGISTIC) to account for the complex sampling design of the NIS-Teen data. All analyses were conducted in 2014.

\section{Results}

\section{Sample characteristics}

Overall, $51.1 \%$ (95\% CI: $50.3 \%-52.0 \%$ ) of the female adolescents were completely unvaccinated for HPV [2008: 61.0\% (95\% CI: 58.9\%-63.0\%) ; 2009: 53.9\% (95\% CI: 52.0\%-55.7.0\%) ; 2010: $52.0 \%$ (95\% CI: 50.1\%-53.8\%) ; 2011: 46.8\% (95\% CI: 45.1\%-48.4\%) ; 2012: 42.0\% (95\% CI: $40.1 \%-43.7 \%)]$. The mean age of these adolescents was 14.3 years. Table 2 presents the socio-demographic characteristics of the unvaccinated adolescent females in this study. Sixty percent were White non-Hispanic, $71.6 \%$ of mothers of unvaccinated females were married, $33.6 \%$ were college graduates, and $46.6 \%$ of were between the ages $35-44$. Sixty-three percent reported that a healthcare provider had not recommended that their daughter receive the HPV vaccine series.

\section{Socio-demographic factors associated with no-intent to receive the HPV vaccine series}

During 2008-2012, 59.9\% (95\% CI: 58.7\%-61.1\%) of parents of unvaccinated adolescent females indicated that they did not intend to have their daughters vaccinated against HPV within the next 12 months. Table 3 describes the socio-demographic characteristics of unvaccinated females across "no-intent" vs. "intent" groups and presents the factors significantly associated with parents' "no-intent" to vaccinate their daughters: number of people in the household (Adjusted Odds Ratio: AOR: 1.05 [95\% CI: 1.01-1.10]); annual household income of \$35,001-\$75,000 (AOR: 1.21 [95\% CI: 1.02-1.44]) compared to $\leq \$ 35,000$; mothers with some college education (AOR: 1.44 [95\% CI: 1.16-1.79]) or who are college graduates (AOR: 1.28 [95\% CI: 1.03-1.60]) compared to mothers with less than high school education ; mothers $\geq 45$ years of age (AOR: 1.32 [95\% CI: 1.06-1.65]) compared to younger mothers ( $\leq 34$ years); "Other" insurance (AOR: 1.36 [95\% CI: 1.05-1.75]) compared to private insurance; no recommendation from a health care provider (AOR: 2.02 [95\% CI: 1.82-2.53]) compared to recommendation from a health care provider; and the survey year, 2009 (AOR: 1.30 [95\% CI: 1.10-1.52]), 2010 (AOR: 1.57 [95\% CI: 1.33-1.86]), 2011 (AOR: 1.25 [95\% CI: $1.06-1.47]$ ), and 2012 (AOR: 1.26 [95\% CI: $1.06-$ 1.50]) compared to survey year 2008. Parents who identified as Hispanics were significantly less likely to report no-intent to vaccinate their daughters (AOR: 0.79 [95\% CI: 0.66-0.95]) compared to White, non-Hispanics.

\section{Patterns in no-intent to receive the HPV vaccine series, 2008-2012}

Table 4 presents patterns across survey years in parental "no-intent" for their daughters to receive the HPV vaccine series within the next 12 months, by sociodemographic characteristics. Among parents who did 
Table 2 Sample characteristics of unvaccinated ${ }^{a}$ female adolescents aged 13-17 years against human papillomavirus (HPV), National Immunization Survey - Teen, 2008 - 2012 $(n=21,467)$

\begin{tabular}{llll}
\hline Characteristics & $n$ & $\begin{array}{l}\text { Weighted \% or } \\
\text { median estimate }\end{array}$ & $\begin{array}{l}95 \% \text { confidence } \\
\text { interval }\end{array}$
\end{tabular}

Adolescent age, years

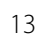

14

15

15

16

17

Race/ethnicity

White, non-Hispanic

Black, non-Hispanic

Hispanic

$5,105 \quad 22.9$

$4,722 \quad 21.1$

4,256 20.7

$3,936 \quad 19.2$

$3,448 \quad 16.1$

15,036

60.1

2,385 $\quad 15.5$

$2,393 \quad 16.8$

Other $^{b}$

$1,663 \quad 7.6$

Number of people in

the household

$21,467 \quad 3.8$

Annual household

income, US dollars

$\leq 35,000$
$35,001-75,000$
$>75,000$

$4,973 \quad 30.8$

$7,055 \quad 32.5$

$9,439 \quad 36.7$

Mother's education

Less than high school

High school

1,859

12.9

Some college

College graduate

4,321

26.9

$6,393 \quad 26.8$

$8,894 \quad 33.6$

Mother's marital status

Married

16,518

Other ${ }^{c}$

4,949

71.6

28.4

Mother's age, years

$\leq 34$

1,518

8.9

35-44

9,263

46.6

$\geq 45$

$10,686 \quad 44.4$

Health insurance status $^{d}$

Private

14,916

63.5

SCHIP or Medicaid

IHS or Military

Other

$3,732 \quad 22.5$

$347 \quad 1.2$

$1,123 \quad 4.8$

Uninsured

$1,349 \quad 8.0$

Healthcare provider recommended the HPV vaccine

$\begin{array}{llll}\text { No } & 12,952 & 63.1 & (61.9-64.3) \\ \text { Yes } & 8,515 & 36.9\end{array}$

$(58.9-61.4)$

(14.5-16.4)

$(15.7-17.9)$

$(6.9-8.3)$

$(3.7-3.8)$

$(29.5-32.0)$

$(31.3-33.7)$

(35.6-37.9)

(11.9-14.0)

$(25.5-27.9)$

$(25.6-27.8)$

(32.5-34.7)

(70.4-72.8)

$(27.2-29.6)$

(8.1-9.7)

45.4-47.9)

$(43.2-45.7)$

$(62.20-64.8)$

(21.4-23.7)

(1.0-1.3)

(4.2-5.4)

$(7.3-8.8)$
Table 2 Sample characteristics of unvaccinated ${ }^{\mathrm{a}}$ female adolescents aged 13-17 years against human papillomavirus (HPV), National Immunization Survey - Teen, 2008 - 2012 $(n=21,467)$ (Continued)

\begin{tabular}{llll}
\hline Survey year & & & \\
2008 & 4,605 & 24.0 & $(22.9-25.2)$ \\
2009 & 4,424 & 21.0 & $(20.0-22.0)$ \\
2010 & 4,173 & 20.0 & $(19.0-21.0)$ \\
2011 & 4,761 & 18.4 & $(17.5-19.3)$ \\
2012 & 3,504 & 16.6 & $(15.7-17.5)$ \\
\hline
\end{tabular}

aHas had zero doses of HPV vaccine

b Includes non-Hispanic other racial/ethnic groups and biracial

${ }^{c}$ Never married/widowed/divorced/separated

${ }^{d}$ SCHIP = State Children's Health Insurance Program; IHS = Indian Health Service

not receive a health care provider recommendation for their daughter to receive the HPV vaccine series, the proportion of parents who reported "no-intent" was significantly lower in survey year 2012 (35.0\%, 95\% CI: $32.2-37.7 \%)$ when compared to survey years 2008 (44.3\%, 95\% CI: (41.5-47.2\%), 2009 (42.0\%, 95\% CI: 39.2-44.8\%), and 2010 (44.9\%, 95\% CI: 42.2-47.6\%). Additionally, there was a significant increase through survey years 2009-2012 when compared to survey year 2008 among the following factors: mothers with a college education, mothers 45 years of age or older, and higher income were all associated with an increase in the proportion of parents who reported "no-intent".

\section{Factors associated with reasons for "no-intent" to receive the HPV vaccine series}

Of the 12,274 parents who reported "no-intent" for their daughters to receive the HPV vaccine series within the next 12 months, $92.3 \%$ of parents cited one reason, $6.6 \%$ cited two, and $1.1 \%$ cited three or more reasons with the maximum being seven reasons. The proportion of parents who reported one or more reasons which fall in one of more of the five domains are as follows: $43.8 \%$ vaccine misinformation, $18.0 \%$ safety and effective concerns, $17.0 \%$ lack of knowledge about the vaccine, 16.0\% systemic barriers, $5.5 \%$ socio-cultural reasons.

Socio-demographic factors associated with parental reasons for "no-intent" for their daughters to receive the HPV vaccine series within the next 12 months is presented in Table 5. Lack of knowledge about the vaccine as a reason for "no-intent" were significantly greater among female adolescents 15 years of age (AOR: 1.37 [95\% CI: $1.05-1.80]$ ), and 16 years of age (AOR: 1.52 [95\% CI: 1.13-2.05]) compared to 13 years of age; Black non-Hispanics (AOR: 1.42 [95\% CI: 1.09-1.86]), Hispanics (AOR: 1.58 [95\% CI: 1.14-2.17]), and Other race/ ethnicity (AOR: 1.45 [95\% CI: 1.04-2.00]) compared to White non-Hispanic parents; mothers $\geq 45$ years of age 
Table 3 Factors associated with no-intent to receive ${ }^{a}$ the human papillomavirus vaccine (HPV) series among unvaccinated female adolescents aged 13-17 years, 2008-2012 national immunization survey-teen $(n=21,467)$

\begin{tabular}{|c|c|c|c|}
\hline \multirow[t]{2}{*}{ Characteristics } & \multicolumn{2}{|c|}{ Unadjusted weighted proportion (95\% Cl) or median } & \multirow{2}{*}{$\begin{array}{l}\text { Adjusted odds ratio ( } 95 \% \\
\text { confidence interval) }\end{array}$} \\
\hline & No-intent to initiate $(n=12,716)$ & Intent-to-initiate $(n=8,751)$ & \\
\hline \multicolumn{4}{|l|}{ Adolescent age, years } \\
\hline 13 & $23.0(21.7-24.4)$ & $22.8(21.2-24.3)$ & 1.00 \\
\hline 14 & $20.9(19.6-22.2)$ & $21.3(19.8-22.9)$ & $0.96(0.83-1.12)$ \\
\hline 15 & $19.9(18.6-21.2)$ & $22.0(20.2-23.7)$ & $0.88(0.75-1.03)$ \\
\hline 16 & $20.0(18.6-21.5)$ & $18.0(16.5-19.6)$ & $1.06(0.90-1.25)$ \\
\hline 17 & $16.1(15.1-17.2)$ & $15.9(14.5-17.3)$ & $0.93(0.79-1.10)$ \\
\hline \multicolumn{4}{|l|}{ Race/ethnicity of teen } \\
\hline White, non-Hispanic & $62.0(60.3-63.6)$ & $57.4(55.4-59.4)$ & 1.00 \\
\hline Black, non-Hispanic & $15.3(14.1-16.4)$ & $15.8(14.2-17.3)$ & $0.96(0.81-1.12)$ \\
\hline Hispanic & $15.2(13.8-16.6)$ & $19.3(17.5-21.1)$ & $0.79(0.66-0.95)$ \\
\hline Other ${ }^{b}$ & $7.6(6.8-8.5)$ & $7.6(6.3-8.9)$ & $0.96(0.76-1.22)$ \\
\hline $\begin{array}{l}\text { Number of people in the household } \\
\text { per person over two }\end{array}$ & $3.79(3.74-3.84)$ & $3.75(3.69-3.81)$ & $1.05(1.01-1.10)$ \\
\hline \multicolumn{4}{|l|}{ Annual household, US dollars } \\
\hline$\leq 35,000$ & $28.4(26.7-29.8)$ & $34.2(32.5-36.5)$ & 1.00 \\
\hline $35,001-75,000$ & $34.2(32.7-35.7)$ & $30.0(28.2-31.8)$ & $1.21(1.02-1.44)$ \\
\hline$>75,000$ & $37.5(36.0-39.1)$ & $35.5(33.8-37.3)$ & $1.08(0.90-1.30)$ \\
\hline \multicolumn{4}{|l|}{ Mother's education } \\
\hline Less than high school & $11.4(10.1-12.7)$ & $15.3(13.6-16.9)$ & 1.00 \\
\hline High school & $25.9(24.4-27.4)$ & $27.9(26.0-29.8)$ & $1.11(0.89-1.39)$ \\
\hline Some college & $28.3(26.9-29.7)$ & $24.5(22.9-26.1)$ & $1.44(1.16-1.79)$ \\
\hline College graduate & $34.4(33.0-35.9)$ & $32.4(30.7-34.0)$ & $1.28(1.03-1.60)$ \\
\hline \multicolumn{4}{|l|}{ Mother's marital status } \\
\hline Other $^{c}$ & 26.5 (24.9-28.1) & $31.3(29.4-33.2)$ & 1.00 \\
\hline Married & 73.5 (71.9-75.1) & $68.7(66.9-70.6)$ & $1.13(0.98-1.31)$ \\
\hline \multicolumn{4}{|l|}{ Mother's age, years } \\
\hline$\leq 34$ & $7.9(7.0-8.8)$ & $10.5(9.1-11.8)$ & 1.00 \\
\hline $35-44$ & $46.4(44.8-48.1)$ & $47.0(45.0-48.9)$ & $1.22(0.99-1.51)$ \\
\hline$\geq 45$ & $45.7(44.1-47.3)$ & $42.6(40.7-44.5)$ & $1.32(1.06-1.65)$ \\
\hline \multicolumn{4}{|l|}{ Health insurance status ${ }^{d}$} \\
\hline Private & $64.8(63.2-66.4)$ & $61.5(59.5-63.5)$ & 1.00 \\
\hline SCHIP or Medicaid & $20.7(19.3-22.1)$ & $25.3(23.3-27.2)$ & $0.92(0.77-1.11)$ \\
\hline IHS or Military & 1. $(0.8-1.2)$ & $1.4(1.0-1.7)$ & $0.73(0.52-1.03)$ \\
\hline Other & $5.4(4.5-6.4)$ & $3.9(3.1-4.7)$ & $1.36(1.05-1.75)$ \\
\hline Uninsured & $8.1(7.1-9.1)$ & $8.0(6.8-9.2)$ & $1.06(0.84-1.35)$ \\
\hline \multicolumn{4}{|l|}{$\begin{array}{l}\text { Health care provider recommended } \\
\text { the HPV vaccine }\end{array}$} \\
\hline Yes & $31.2(29.8-32.7)$ & $45.4(43.5-47.3)$ & 1.00 \\
\hline No & $68.8(67.3-70.3)$ & $54.6(52.7-56.5)$ & $2.02(1.82-2.53)$ \\
\hline \multicolumn{4}{|l|}{ Survey year } \\
\hline 2008 & $22.4(21.0-23.9)$ & $26.4(24.5-28.3)$ & 1.00 \\
\hline
\end{tabular}


Table 3 Factors associated with no-intent to receive ${ }^{a}$ the human papillomavirus vaccine (HPV) series among unvaccinated female adolescents aged 13-17 years, 2008-2012 national immunization survey-teen $(n=21,467)$ (Continued)

\begin{tabular}{llll}
\hline 2009 & $21.4(19.8-22.8)$ & $20.5(19.0-22.0)$ & $1.30(1.10-1.52)$ \\
2010 & $21.7(20.4-23.1)$ & $17.4(16.0-18.9)$ & $1.57(1.33-1.86)$ \\
2011 & $18.2(17.1-19.3)$ & $18.8(17.3-20.2)$ & $1.25(1.06-1.47)$ \\
2012 & $16.3(15.4-17.4)$ & $17.0(15.5-18.4)$ & $1.26(1.06-1.50)$ \\
\hline
\end{tabular}

${ }^{a}$ No-intent to initiate the HPV vaccine series in the next 12 months

b Includes non-Hispanic other racial/ethnic groups and biracial

${ }^{c}$ Never married/widowed/divorced/separated/deceased

${ }^{\mathrm{d}} \mathrm{SCHIP}=$ State Children's Health Insurance Program; IHS = Indian Health Service

(AOR: 1.48 [95\% CI: $1.00-2.22]$ ) and 35-44 years of age (AOR: 1.56 [95\% CI: 1.06-2.31]) compared to mothers ( $\leq 34$ years of age. Compared to mothers with less than high school education, mothers with high school education (AOR: 1.52 [95\% CI: 1.02-2.28]), some college education (AOR: 1.79 [95\% CI: 1.20-2.68]), or with a graduate education (AOR: 1.84 [95\% CI: 1.21-2.81]) had greater odds to report "Safety and Effectiveness Concerns".

Parents who did not receive a health care provider recommendation for their daughter to receive the HPV vaccine series had greater odds to report "Systemic Barriers" (AOR: 6.84 [95\% CI: 5.25-8.91]) and/ or "Vaccine Misinformation" (AOR: 1.18 [95\% CI: 1.02-1.35]) compared to those parents of female adolescents with a provider recommendation. An increasing number of people in the household was also associated with greater odds to report vaccine misinformation (AOR: 1.08 [95\% CI: 1.03-1.14]).

The odds of reporting "Socio-cultural Barriers" were significantly greater among female adolescents 15 years of age (AOR: 1.57 [95\% CI: 1.09-2.26]) and, 17 years of age (AOR: 1.52 [95\% CI: 1.01-2.30]) compared to 13 years of age; among Black non-Hispanic parents (AOR: 1.63 [95\% CI: 1.15-2.32]) compared to White nonHispanic parents; among parents who reported their annual household income as $>\$ 75,000$ (AOR: 1.91 [95\% CI: $1.14-3.19]$ ), and \$35,001-\$75,000 (AOR: 1.62 [95\% CI: 1.04-2.55]) compared to parents who reported their annual household income as $\leq \$ 35,000$. Parents in survey years 2009-2012 were more likely to report safety and effectiveness concerns compared to parents in the survey year 2008. Additionally, parents in the survey year 2012 (AOR: 1.57 [95\% CI: 1.17-2.09]) had higher odds of reporting systemic barriers compared to parents in the survey year 2008 .

\section{Discussion}

This study is one of the first to identify sub-groups of parents across different socio-demographic factors who reported "no-intent" and reasons for "no-intent" for their daughters to receive the HPV vaccine series within the next 12 months in a nationally representative sample of unvaccinated female adolescents 13-17 years of age.
Though the proportion of HPV vaccine uptake among female adolescents has significantly increased over time, this study found that three out of five parents of unvaccinated females reported "no-intent" to vaccinate their daughters within the next 12 months (2008: 55.1\% ; 2009: $60.6 \%$; 2010: 64.6\% ; 2011: 59.8\% ; 2012: 60.3\%). In addition, this study describes the patterns over time in socio-demographic factors of parents who reported "no-intent". The study findings provide useful information to develop strategies for outreach and education geared toward health care providers whose lack of recommendation for the HPV vaccine significantly influenced parental "intent" for their daughters to receive the HPV vaccine series, to address parents' concerns about the HPV vaccine across different socio-demographic characteristics. This may help improve the vaccine uptake among females 13-17 years of age.

Consistent with previous reports [25, 32, 39-41], provider recommendation was observed to significantly influence parental "intent" for their daughters to receive the HPV vaccine series; more than sixty percent of parents of unvaccinated females received no recommendation from their health care provider (2008: 70.1\% ; 2009: 62.8\% ; 2010: 63.4\% ; 2011: 60.3\% ; 2012: 55.9\%). Among parents with "no-intent" who reported systemic barriers, $21.6 \%$ received a provider recommendation, compared to $3.9 \%$ of parents who did not receive a provider recommendation for their adolescent daughters. Among parents with "no-intent" who reported Safety and Effectiveness Concerns, $28.1 \%$ received a provider recommendation compared to $13.3 \%$ of parents who did not receive a provider recommendation for their adolescent daughters. Lastly, compared to parents in the survey year 2008, parents in the survey years 2009-2012 were significantly more likely to report "no-intent" and cite Safety and Effectiveness Concerns as their reason, yet less like to cite Lack of Knowledge about the Vaccine as a reason for "no-intent". This may suggest that over time knowledge about the vaccine has increased, but along with that the safety and effectiveness concerns have also increased. These findings not only highlight the importance of a provider recommendation, but also the missed 
Table 4 Patterns in no-intent ${ }^{a}$ for the HPV vaccine according to socio-demographic factors, National Immunization Survey - Teen, $2008-2012(n=21,467)$

\begin{tabular}{|c|c|c|c|c|c|}
\hline \multirow[b]{2}{*}{ Socio-demographic Factor } & \multicolumn{5}{|c|}{ Survey year } \\
\hline & $\begin{array}{c}2008 \\
(n=4,605)\end{array}$ & $\begin{array}{c}2009 \\
(n=4,424)\end{array}$ & $\begin{array}{c}2010 \\
(n=4,173)\end{array}$ & $\begin{array}{c}2011 \\
(n=4,761)\end{array}$ & $\begin{array}{c}2012 \\
(n=3,504)\end{array}$ \\
\hline \multicolumn{6}{|l|}{ Age, years } \\
\hline 13 & $12.3(10.4-14.1)$ & $13.7(11.8-15.5)$ & $15.2(13.3-17.1)$ & $14.2(12.5-15.9)$ & $14.0(12.0-15.9)$ \\
\hline 14 & $11.4(9.4-13.3)$ & $13.8(11.8-15.8)$ & $12.4(10.5-14.3)$ & $12.8(11.1-14.4)$ & $12.3(10.5-14.1)$ \\
\hline 15 & $11.0(9.2-12.9)$ & $12.3(10.7-14.0)$ & $13.5(11.6-15.5)$ & $11.4(10.0-12.9)$ & $11.3(9.5-13.1)$ \\
\hline 16 & $11.9(10.0-13.8)$ & $11.9(9.4-14.3)$ & $12.1(10.3-13.9)$ & $12.4(10.5-14.2)$ & $11.7(9.7-13.8)$ \\
\hline 17 & $9.3(7.8-10.8)$ & $9.2(7.9-10.5)$ & $11.8(10.1-13.5)$ & $8.4(7.2-9.5)^{c}$ & $9.6(7.8-11.3)$ \\
\hline \multicolumn{6}{|l|}{ Race/ethnicity } \\
\hline White, non-Hispanic & $33.9(31.3-36.5)$ & $38.4(35.8-41.0)$ & $39.7(37.1-42.2)$ & $38.2(35.8-40.5)$ & $35.8(33.2-38.4)$ \\
\hline Black, non-Hispanic & $9.0(7.5-10.5)$ & $8.9(7.5-10.3)$ & $10.9(9.2-12.6)$ & $8.3(6.8-9.8)$ & $8.5(6.6-10.3)$ \\
\hline Hispanic & $9.5(7.4-11.6)$ & $9.5(7.2-11.8)$ & $10.2(8.0-12.3)$ & $7.7(6.3-9.1)$ & $8.2(6.5-10.0)$ \\
\hline Other ${ }^{b}$ & $3.5(2.5-4.4)$ & $4.1(3.1-5.1)$ & $4.4(3.4-5.4)$ & $5.0(3.7-6.2)$ & $6.5(4.8-8.1)$ \\
\hline \multicolumn{6}{|c|}{ Annual household income, US \$ } \\
\hline$\leq 35,000$ & $15.8(13.5-18.2)$ & $15.6(13.5-17.7)$ & $19.2(16.8-21.7)$ & $17.8(15.8-19.9)$ & $16.4(13.9-18.8)$ \\
\hline $35,001-75,000$ & $20.3(18.1-22.5)$ & $20.8(18.3-23.2)$ & $20.7(18.7-22.8)$ & $21.0(18.9-23.2)$ & $19.4(17.1-21.6)$ \\
\hline$>75,000$ & $19.7(17.6-21.9)$ & $24.6(22.2-26.9)^{\mathrm{e}}$ & $25.1(22.8-27.3)^{\mathrm{e}}$ & $20.2(18.5-21.9)^{f, g}$ & $23.2(20.9-25.4)$ \\
\hline \multicolumn{6}{|l|}{ Mother's education } \\
\hline Less than high school & $8.1(6.0-10.1)$ & $6.9(5.3-8.5)$ & $7.6(5.6-9.7)$ & $5.2(4.0-6.4)$ & $5.6(3.8-7.4)$ \\
\hline High school & $15.3(13.3-17.4)$ & $16.6(13.9-19.3)$ & $16.9(14.9-18.9)$ & 15.6(13.6-17.6) & $12.5(10.6-14.4)$ \\
\hline Some college & $15.7(13.8-17.6)$ & $15.9(14.2-17.5)$ & $18.9(16.9-20.9)$ & $16.5(14.7-18.2)$ & $18.3(16.0-20.6)$ \\
\hline College graduate & $16.8(14.8-18.8)$ & $21.6(19.5-23.6)^{\mathrm{e}}$ & $21.5(19.4-23.6)^{\mathrm{e}}$ & $21.9(19.9-23.8)^{\mathrm{e}}$ & $22.5(20.3-24.7)^{e}$ \\
\hline \multicolumn{6}{|l|}{ Mother's marital status } \\
\hline Married & $42.2(39.4-45.1)$ & $46.7(44.0-49.4)$ & $48.9(46.1-51.6)$ & $40.9(38.5-43.3)$ & 40.7 (37.9-43.5) \\
\hline Other ${ }^{c}$ & $13.7(11.5-15.8)$ & $14.2(11.7-16.7)$ & $16.2(14.0-18.3)$ & $18.2(16.0-20.4)^{\mathrm{e}}$ & $18.2(15.6-20.8)$ \\
\hline \multicolumn{6}{|l|}{ Mother's age, years } \\
\hline$\leq 34$ & $4.5(3.2-5.7)$ & $3.7(2.9-4.6)$ & $5.5(4.1-7.0)$ & $5.5(4.1-6.8)$ & $4.4(3.1-5.7)$ \\
\hline $35-44$ & $28.1(25.4-30.8)$ & $29.1(26.4-31.8)$ & $28.7(26.1-31.3)$ & $26.6(24.4-28.8)$ & $25.9(23.3-28.5)$ \\
\hline$\geq 45$ & $23.3(21.1-25.1)$ & $28.0(25.6-30.5)^{\mathrm{e}}$ & $30.8(28.4-33.2)^{\mathrm{e}}$ & $27.0(24.8-29.2)$ & $28.6(26.0-31.1)^{\mathrm{e}}$ \\
\hline \multicolumn{6}{|l|}{ Health insurance status ${ }^{d}$} \\
\hline Private & $37.0(34.3-39.7)$ & $40.0(37.4-42.7)$ & $41.4(38.8-44.0)$ & $37.9(35.5-40.4)$ & $37.6(34.8-40.3)$ \\
\hline SCHIP or Medicaid & $11.5(9.4-13.5)$ & $10.2(8.7-11.7)$ & $13.7(11.6-15.9)$ & $13.2(11.5-14.9)$ & $13.8(11.4-16.1)$ \\
\hline IHS or Military & $0.4(0.2-0.6)$ & $0.7(0.4-1.0)$ & $0.8(0.5-1.1)$ & $0.6(0.3-0.8)$ & $0.6(0.2-1.0)$ \\
\hline Other & $2.4(1.7-3.0)$ & $5.0(2.9-7.1)$ & $2.5(1.9-3.1)$ & $3.3(2.3-4.2)$ & $3.3(2.3-4.3)$ \\
\hline Uninsured & $4.6(3.2-6.1)$ & $5.0(3.6-6.3)$ & $6.6(4.8-8.4)$ & $4.1(3.2-5.1)$ & $3.7(2.7-4.7)$ \\
\hline \multicolumn{6}{|c|}{ Healthcare provider recommended HPV vaccine } \\
\hline Yes & $11.6(9.9-13.2)$ & $18.9(16.7-21.1)$ & $20.1(17.8-22.5)$ & $21.5(19.4-23.6)$ & $24.0(21.5-26.4)$ \\
\hline No & $44.3(41.5-47.2)$ & $42.0(39.2-44.8)$ & $44.9(42.2-47.6)$ & $37.6(35.2-40.0)$ & $35.0(32.2-37.7)^{\mathrm{e}, \mathrm{f}, \mathrm{g}}$ \\
\hline
\end{tabular}

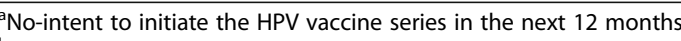

bincludes non-Hispanic other racial/ethnic groups and biracial

${ }^{c}$ Never married/widowed/divorced/separated

${ }^{\mathrm{d}} \mathrm{SCHIP}=$ State Children's Health Insurance Program; IHS = Indian Health Service

'Significantly different compared to the survey year 2008

fSignificantly different compared to the survey year 2009

${ }^{9}$ Significantly different compared to the survey year 2010 
Table 5 Multivariable logistic regression analyses of factors associated with reasons for no-intent to receive ${ }^{a}$ human papillomavirus vaccine (HPV) series among unvaccinated female adolescents aged 13-17 years, National Immunization Survey - Teen, 2008-2012 $\left(n=12,274^{\mathrm{b}}\right)$

\begin{tabular}{|c|c|c|c|c|c|}
\hline \multirow[b]{2}{*}{ Factors } & \multicolumn{5}{|c|}{ Adjusted odds ratio $(95 \% \text { confidence interval) })^{c}$} \\
\hline & $\begin{array}{c}\text { Safety and Effectiveness } \\
\text { Concerns }^{\mathrm{d}}\end{array}$ & $\begin{array}{l}\text { Systemic } \\
\text { Barriers }^{\mathrm{e}}\end{array}$ & $\begin{array}{c}\text { Vaccine } \\
\text { Misinformation }^{f} \\
\end{array}$ & $\begin{array}{l}\text { Lack of Knowledge } \\
\text { about the Vaccine }^{9}\end{array}$ & $\begin{array}{l}\text { Socio-cultural } \\
\text { reasons }\end{array}$ \\
\hline \multicolumn{6}{|l|}{ Age, years } \\
\hline 13 & 1.00 & 1.00 & 1.00 & 1.00 & 1.00 \\
\hline 14 & $0.99(0.78-1.27)$ & $1.15(0.86-1.52)$ & $0.90(0.74-1.10)$ & $1.27(0.95-1.70)$ & $0.78(0.54-1.13)$ \\
\hline 15 & $0.94(0.75-1.19)$ & $0.93(0.69-1.24)$ & $0.88(0.72-1.08)$ & $1.37(1.05-1.80)$ & $1.57(1.09-2.26)$ \\
\hline 16 & $1.01(0.79-1.30)$ & $0.84(0.63-1.13)$ & $0.76(0.61-0.93)$ & $1.52(1.13-2.05)$ & $1.29(0.82-2.01)$ \\
\hline 17 & $1.00(0.78-1.29)$ & $1.01(0.76-1.36)$ & $0.69(0.56-0.84)$ & $1.10(0.83-1.47)$ & $1.52(1.01-2.30)$ \\
\hline \multicolumn{6}{|l|}{ Race/ethnicity } \\
\hline White, non-Hispanic & 1.00 & 1.00 & 1.00 & 1.00 & 1.00 \\
\hline Black, non-Hispanic & $0.75(0.57-0.98)$ & $1.05(0.78-1.41)$ & $0.98(0.80-1.20)$ & $1.42(1.09-1.86)$ & $1.63(1.15-2.32)$ \\
\hline Hispanic & $0.80(0.59-1.10)$ & $1.02(0.75-1.38)$ & $0.93(0.73-1.19)$ & $1.58(1.14-2.17)$ & $1.14(0.72-1.81)$ \\
\hline Other' & $0.70(0.52-0.94)$ & $1.39(1.00-1.94)$ & $0.80(0.62-1.02)$ & $1.45(1.04-2.00)$ & $0.88(0.54-1.44)$ \\
\hline $\begin{array}{l}\text { Number of people in the household, } \\
\text { per person over two }\end{array}$ & $0.86(0.81-0.91)$ & $0.97(0.91-1.04)$ & $1.08(1.03-1.14)$ & $1.00(0.92-1.09)$ & $1.09(0.98-1.22)$ \\
\hline \multicolumn{6}{|l|}{ Annual household income, US \$ } \\
\hline$\leq 35,000$ & 1.00 & 1.00 & 1.00 & 1.00 & 1.00 \\
\hline $35,001-75,000$ & $1.13(0.88-1.47)$ & $0.64(0.49-0.83)$ & $1.03(0.84-1.27)$ & $1.20(0.91-1.59)$ & $1.62(1.04-2.55)$ \\
\hline$>75,000$ & $1.10(0.84-1.46)$ & $0.62(0.46-0.83)$ & $1.04(0.83-1.31)$ & $0.95(0.70-1.30)$ & $1.91(1.14-3.19)$ \\
\hline \multicolumn{6}{|l|}{ Mother's education } \\
\hline Less than high school & 1.00 & 1.00 & 1.00 & 1.00 & 1.00 \\
\hline High school & $1.52(1.02-2.28)$ & $0.77(0.52-1.13)$ & $1.12(0.82-1.53)$ & $0.95(0.66-1.38)$ & $1.18(0.58-2.43)$ \\
\hline Some college & $1.79(1.20-2.68)$ & $0.76(0.53-1.10)$ & $1.24(0.91-1.68)$ & $0.76(0.53-1.08)$ & $1.32(0.67-2.59)$ \\
\hline College graduate & $1.84(1.21-2.81)$ & $0.82(0.56-1.20)$ & $1.51(1.10-2.06)$ & $0.48(0.34-0.69)$ & $1.55(0.74-3.24)$ \\
\hline \multicolumn{6}{|l|}{ Mother's marital status } \\
\hline Other & 1.00 & 1.00 & 1.00 & 1.00 & 1.00 \\
\hline Married & $1.22(0.98-1.52)$ & $1.18(0.92-1.52)$ & $1.09(0.88-1.34)$ & $0.88(0.63-1.22)$ & $0.71(0.51-0.98)$ \\
\hline \multicolumn{6}{|l|}{ Mother's age, years } \\
\hline$\leq 34$ & 1.00 & 1.00 & 1.00 & 1.00 & 1.00 \\
\hline $35-44$ & $0.99(0.71-1.36)$ & $0.91(0.63-1.33)$ & $0.85(0.64-1.13)$ & $1.56(1.06-2.31)$ & $0.55(0.31-0.98)$ \\
\hline$\geq 45$ & $0.86(0.62-1.21)$ & $0.98(0.67-1.43)$ & $0.92(0.69-1.23)$ & $1.48(1.00-2.22)$ & $0.56(0.31-1.01)$ \\
\hline \multicolumn{6}{|l|}{ Health insurance status ${ }^{k}$} \\
\hline Private & 1.00 & 1.00 & 1.00 & 1.00 & 1.00 \\
\hline SCHIP or Medicaid & $1.21(0.93-1.56)$ & $0.97(0.73-1.30)$ & $0.83(0.66-1.02)$ & $0.73(0.54-1.00)$ & $1.34(0.86-2.07)$ \\
\hline IHS or Military & $1.20(0.71-2.06)$ & $0.76(0.35-1.70)$ & $0.75(0.47-1.19)$ & $0.83(0.42-1.64)$ & $1.63(0.76-3.49)$ \\
\hline Other & $0.88(0.63-1.22)$ & $0.99(0.66-1.47)$ & $0.87(0.64-1.19)$ & $1.32(0.77-2.27)$ & $1.31(0.74-2.34)$ \\
\hline Uninsured & $0.98(0.69-1.38)$ & $1.06(0.73-1.52)$ & $0.86(0.65-1.15)$ & $1.30(0.91-1.88)$ & $0.69(0.38-1.25)$ \\
\hline \multicolumn{6}{|c|}{ Healthcare provider recommended HPV vaccine } \\
\hline Yes & 1.00 & 1.00 & 1.00 & 1.00 & 1.00 \\
\hline No & $0.42(0.36-0.49)$ & $6.84(5.25-8.91)$ & $1.18(1.02-1.35)$ & $0.86(0.69-1.07)$ & $0.49(0.38-0.63)$ \\
\hline \multicolumn{6}{|l|}{ Survey Year } \\
\hline 2008 & 1.00 & 1.00 & 1.00 & 1.00 & 1.00 \\
\hline 2009 & $1.45(1.09-1.93)$ & $0.93(0.70-1.24)$ & $0.80(0.64-0.99)$ & $0.96(0.71-1.30)$ & $2.07(1.39-3.07)$ \\
\hline
\end{tabular}


Table 5 Multivariable logistic regression analyses of factors associated with reasons for no-intent to receive human papillomavirus vaccine (HPV) series among unvaccinated female adolescents aged 13-17 years, National Immunization Survey - Teen, 2008-2012 $\left(n=12,274^{\mathrm{b}}\right)$ (Continued)

\begin{tabular}{llllll}
\hline 2010 & $2.83(2.16-3.70)$ & $0.93(0.70-1.24)$ & $0.85(0.69-1.04)$ & $0.63(0.47-0.85)$ & $0.95(0.60-1.52)$ \\
2011 & $2.18(1.68-2.83)$ & $0.87(0.65-1.16)$ & $1.02(0.83-1.25)$ & $0.66(0.50-0.87)$ & $1.14(0.75-1.72)$ \\
2012 & $1.45(1.09-1.93)$ & $1.57(1.17-2.09)$ & $0.67(0.53-0.84)$ & $0.64(0.47-0.87)$ & $1.47(0.95-2.27)$ \\
\hline
\end{tabular}

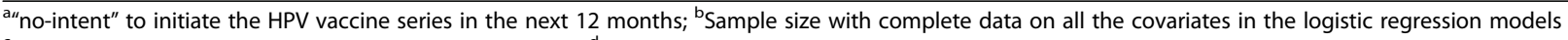
cLogistic regression models include all the variables listed; dSafety and effectiveness concerns category included the cited reasons of safety and side effects, new

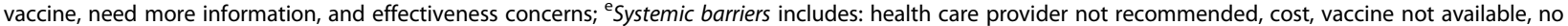
doctor/obstetrician/gynecologist/doctor visit scheduled, and not a school requirement; ${ }^{\mathrm{f}}$ Vaccine misinformation includes: not needed/not necessary, adolescent not sexually active, not appropriate age, and concern of increased sexual activity; ${ }^{9}$ lack of knowledge about the vaccine included the response lack of knowledge;

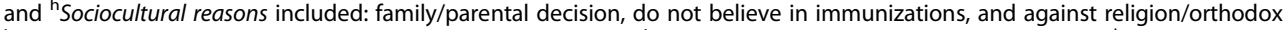

includes non-Hispanic other racial/ethnic groups and biracial; ${ }^{j}$ Never married/widowed/divorced/separated; ${ }^{k}$ SCHIP = State Children's Health Insurance Program; $\mathrm{IHS}=$ Indian Health Service

opportunities health care providers have to effectively communicate the health benefits of the HPV vaccine, specifically with regard to vaccine safety and effectiveness. Additionally, a provider recommendation would help to facilitate an improvement in vaccine acceptance and vaccination intentions [42-45].

In this study, mothers with a high school education or higher were more likely to report "no-intent" for their daughters to receive the HPV vaccine series within the next 12 months. Other studies have reported similar findings [28, 35, 46]. In addition, we found mothers with higher education were more likely to cite Safety and Effectiveness Concerns as a reason for "no-intent". This highlights the importance of appropriately addressing safety and effectiveness concerns among all mothers, particularly those with higher education. Also, we found older mothers were more likely to report "no-intent" compared to younger mothers, and this result is also consistent with other studies [47, 48]. Older mothers, Black non-Hispanic, Hispanic, and parents of "Other" ethnicity were more likely to report "Lack of Knowledge about the Vaccine" as a reason for "no-intent". Consistent with our finding, recent studies in Latino parents' reported low HPV vaccine knowledge as one of the main barriers to vaccine receipt $[41,49]$. Furthermore, parents of older adolescents Black non-Hispanic and parents with annual household income more than $\$ 35,000$, and were more likely to cite "Socio-cultural Barriers". These findings highlight the importance of disseminating health communication about HPV across various demographics.

Overall, this study found that the patterns in sociodemographic factors between proportions of parents reporting "no-intent" were similar across years 20082012. These patterns highlight that HPV vaccine acceptance beliefs among parents have not significantly changed over time, thereby impacting vaccine uptake among certain sub-groups of adolescents identified in this study. Considering that the HPV vaccine is intended to protect against HPV infection and pre-cancerous lesions caused by high-risk HPV types, delaying the initiation or refusing the vaccine altogether by these subgroups of parents for their daughters is a matter of public health concern.

We acknowledge that the analysis of this study has some limitations. In the years 2008-2010, during which cell-phone-only households were increasing, the NISTeen sampling frame included only households that had landline telephones. For the first time in 2011, NIS-Teen utilized a dual-frame (both landline and cell-phone sampling frames) but the cellular household response rate was low compared to the landline household response rate in both 2011 and 2012. As a result, non-response and non-coverage bias may exist, even after adjusting sampling weights. Geographic region in the US, which we did not consider in our study, may be helpful to better understand and address parents' reported reasons for "no-intent" to vaccinate their adolescent daughters [24]. Also, information about adolescent daughter being a first child or not would shed some insights into parents' awareness of HPV vaccine. Lastly, parental no-intent to vaccinate their 13-17 years old daughters within the next 12 months might not necessarily result in not vaccinating beyond the 12-month period, as intention and action often vary.

\section{Conclusions}

This study identified sub-groups of parents across different socio-demographic factors with "no-intent" for their daughters of 13-17 years of age to receive the HPV vaccine series within the next 12 months, and their reasons for such a decision. Developing strategies that target educational tools towards the identified sub-groups of parents about the purpose, safety, and efficacy of the HPV vaccine, and HPV infection, may help increase HPV vaccination acceptance, and initiation and completion rates among female adolescents. In addition, strategies to improve vaccine uptake should focus on developing communication tools for health care providers to better address parents' reasons for "no-intent" 
in support of making recommendations for vaccinating the adolescents during their health-care encounter.

\section{Implications and contribution}

This study identified subgroups of parents across different socio-demographics and the reported reasons for no-intent to vaccinate their daughters with the HPV vaccine. The socio-demographic characteristics of such parents with no-intent as identified in this study have implications for developing strategies to address the various concerns (reasons) reported by the parents with "no-intent" to vaccinate their adolescent daughters with HPV vaccine. Also, communication tools focused on health care providers would address the significant systemic failure due to lack of provider recommendation. These efforts may help increase HPV vaccine acceptance. Future studies should focus on the impact of strategies developed on HPV vaccine uptake among the subgroups of parents identified in this study.

\section{Abbreviations}

AOR: Adjusted Odds Ratio; Cl: Confidence Interval; FDA: Food and Drug Administration; HPV: Human papillomavirus; IHS: Indian Health Service; NIS: National Immunization Survey; SCHIP: State Children's Health Insurance Program; STI: Sexually transmitted infection

\section{Acknowledgements}

None.

\section{Funding}

None.

\section{Availability of data and materials}

The datasets analyzed during the current study available from the corresponding author on reasonable request.

\section{Authors' contributions}

VKC, MPB, LND conceptualized the study. VKC conducted the data analysis, interpreted the results and lead in the writing of the manuscript. MPB and LD contributed to the interpretation of the results and the manuscript writing. All authors read and approved the final manuscript.

\section{Competing interests}

The authors declare that they have no competing interests.

\section{Consent for publication}

Not applicable.

\section{Ethics approval and consent to participate}

This study was exempt from review by Kent State University's IRB because NIS data are publicly available and deidentified.

\section{Received: 7 January 2016 Accepted: 1 February 2017}

Published online: 13 February 2017

\section{References}

1. Markowitz LE, Sternberg M, Dunne EF, McQuillan G, Unger ER. Seroprevalence of human papillomavirus types 6, 11, 16, and 18 in the United States: National Health and Nutrition Examination Survey 2003-2004. J Infect Dis. 2009; 200(7):1059-67.

2. Dunne EF, Unger ER, Sternberg M, et al. Prevalence of HPV infection among females in the United States. JAMA. 2007:297(8):813-9.

3. Forhan SE, Gottlieb SL, Sternberg MR, Xu F, Datta SD, McQuillan GM, Berman SM, Markowitz LE. Prevalence of sexually transmitted infections among female adolescents aged 14 to 19 in the United States. Pedatrics. 2009;124:1505-12.
4. Division of STD Prevention, National Center for HIV/AIDS, Viral Hepatitis, STD, and TB Prevention, Centers for Disease Control and Prevention. Available at http://www.cdc.gov/std/hpv/stdfact-hpv-vaccine-hcp.htm. Accessed 3 Feb 2017.

5. Srodon M, Stoler MH, Baber GB, Kurman RJ. The distribution of low and high-risk HPV types in vulvar and vaginal intraepithelial neoplasia (VIN and ValN). Am J Surg Pathol. 2006;30(12):1513-8.

6. Palefsky JM. Anal squamous intraepithelial lesions: relation to HIV and human papillomavirus infection. JAIDS Journal of Acquired Immune Deficiency Syndromes. 1999;21:S42-8.

7. The FUTURE II Study Group. Quadrivalent vaccine against human papillomavirus to prevent high-grade cervical lesions. N Engl J Med. 2007; 356:1915-27.

8. Centers for Disease Control and Prevention. FDA licensure of bivalent human papillomavirus vaccine (HPV2, Cervarix) for use in females and updated HPV vaccination recommendations from the advisory committee on immunization practices (ACIP). MMWR Morb Mortal Wkly Rep. 2010;59(20):626-9.

9. Markowitz LE, Dunne EF, Saraiya M, Lawson HW, Chesson H, Unger ER. Quadrivalent Human Papillomavirus Vaccine: Recommendations of the Advisory Committee on Immunization Practices (ACIP). MMWR Recomm Rep. 2007:56:1-24.

10. Van Damme P, Olsson SE, Block S, Castellsague X, Gray GE, Herrera T, Huang LM, Kim DS, Pitisuttithum P, Chen J, Christiano S, Maansson R, Moeller E, Sun X, Vuocolo S, Luxembourg A. Immunogenicity and safety of a 9-valent HPV vaccine. Pediatrics. 2015. doi:10.1542/peds.2014-3745.

11. Joura EA, Giuliano AR, Iversen OE, Bouchard C, Mao C, Mehlsen J, Moreira Jr ED, Ngan Y, Petersen LK, Lazcano-Ponce E, Pitisuttithum P, Restrepo JA, Stuart G, Woelber L, Yang YC, Cuzick J, Garland SM, Huh W, Kjaer SK, Bautista OM, Chan IS, Chen J, Gesser R, Moeller E, Ritter M, Vuocolo S, Luxembourg A. A 9-valent HPV vaccine against infection and intraepithelial neoplasia in women. New England Journal of Medicine. 2015;372(8):711-23.

12. U.S. Department of Health and Human Services. 2020 Topics \& Objectives: Immunization and Infectious Diseases. Available at https://www. healthypeople.gov/2020/topics-objectives/topic/immunization-andinfectious-diseases/objectives. Accessed 3 Feb 2017.

13. Markowitz LE, Hariri S, Lin C, Dunne EF, Steinau M, McQuillan G, Unger ER. Reduction in Human Papillomavirus (HPV) Prevalence Among Young Women Following HPV Vaccine Introduction in the United States, National Health and Nutrition Examination Surveys, 2003-2010. J Infect Dis. 2013; 208(3):385-93.

14. Centers for Disease Control and Prevention. Human papillomavirus vaccination coverage among adolescent girls, 2007-2012, and postlicensure vaccine safety monitoring, 2006-2013 - United States. MMWR Morb Mortal Wkly Rep. 2013; 62(29)):591-5.

15. Chao C, Velicer C, Slezak JM, Jacobsen SJ. Correlates for human papillomavirus vaccination of adolescent girls and young women in a managed care organization. Am J Epidemiol. 2010;171(3):357-67.

16. Cook RL, Zhang J, Mullins J, et al. Factors associated with initiation and completion of human papillomavirus vaccine series among young women enrolled in Medicaid. J Adolesc Health. 2010:47(6):596-9.

17. Widdice LE, Bernstein DI, Leonard AC, Marsolo KA, Kahn JA. Adherence to the HPV vaccine dosing intervals and factors associated with completion of 3 doses. Pediatrics. 2010;127(1):77-84.

18. Guerry SL, De Rosa CJ, Markowitz LE, et al. Human papillomavirus vaccine initiation among adolescent girls in high-risk communities. Vaccine. 2011; 29(12):2235-41.

19. Niccolai LM, Mehta NR, Hadler JL. Racial/Ethnic and poverty disparities in human papillomavirus vaccination completion. Am J Prev Med. 2011; 41(4):428-33.

20. Anhang Price $R$, Tiro JA, Saraiya M, Meissner $H$, Breen N. Use of human papillomavirus vaccines among young adult women in the United States: an analysis of the 2008 National Health Interview Survey. Cancer. 2011;117(24):5560-8.

21. Smith LM, Brassard P, Kwong JC, Deeks SL, Ellis AK, Lévesque LE. Factors associated with initiation and completion of the quadrivalent human papillomavirus vaccine series in an Ontario cohort of grade 8 girls. BMC Public Health. 2011;11:645

22. Dorell C, Yankey D, Santibanez T, Markowitz L. Human papillomavirus vaccination series initiation and completion, 2008-2009. Pediatrics. 2011; 128(5):830-9.

23. Kepka D, Ding Q, Warner EL, Spigarelli MG, Mooney K. High school females and those with other vaccinations most likely to complete the Human Papillomavirus vaccine. Preventive medicine reports. 2015;2:79-83. 
24. Henry KA, Stroup AM, Warner EL, Kepka D. Geographic Factors and Human Papillomavirus (HPV) Vaccination Initiation among Adolescent Girls in the United States. Cancer Epidemiol Biomark Prev. 2016;25(2):309-17.

25. Laz TH, Rahman M, Berenson AB. An update on human papillomavirus vaccine uptake among 11-17 year old girls in the United States: National Health Interview Survey, 2010. Vaccine. 2012;30(24):3534-40.

26. Kahn JA, Rosenthal SL, Jin Y, Huang B, Namakydoust A, Zimet GD. Rates of human papillomavirus vaccination, attitudes about vaccination, and human papillomavirus prevalence in young women. Obstet Gynecol. 2008;111:1103-10.

27. Conroy K, Rosenthal SL, Zimet GD, et al. Human papillomavirus vaccine uptake, predictors of vaccination, and self-reported barriers to vaccination. J Womens Health (Larchmt). 2009;18(10)):1679-86.

28. Rosenthal SL, Rupp R, Zimet GD, et al. Uptake of HPV vaccine: Demographics, sexual history and values, parenting style, and vaccine attitudes. J Adolesc Health. 2008:43:239-45.

29. Gerend MA, Weibley E, Bland H. Parental response to human papillomavirus vaccine availability: uptake and intentions. J Adolesc Health. 2009;45(5):528-31.

30. Reiter PL, Katz ML, Paskett ED. Correlates of HPV vaccination among adolescent females from Appalachia and reasons why their parents do not intend to vaccinate. Vaccine. 2013;31(31):3121-5.

31. Zimet GD, Weiss TW, Rosenthal SL, Good MB, Vichnin MD. Reasons for nonvaccination against HPV and future vaccination intentions among 19-26 year-old women. BMC Womens Health. 2010;10:27.

32. Dorell C, Yankey D, Strasser S. Parent-reported reasons for nonreceipt of recommended adolescent vaccinations, National Immunization Survey-Teen. Clin Pediatr. 2009;2011:1-9.

33. Liddon NC, Hood JE, Leichliter JS. Intent to receive HPV vaccine and reasons for not vaccinating among unvaccinated adolescent and young women: findings from the 2006-2008 National Survey of Family Growth. Vaccine. 2012;30(16):2676-82

34. Darden PM, Thompson DM, Roberts JR, Hale JJ, Pope C, Naifeh M, et al. Reasons for not vaccinating adolescents: National Immunization Survey of Teens, 2008-2010. Pediatrics. 2013;131:645-51.

35. Constantine NA, Jerman P. Acceptance of human papillomavirus vaccination among californian parents of daughters: A representative statewide analysis. J Adolesc Health. 2007;40(2):108-15.

36. Trim K, Nagji N, Elit L, Roy K. Parental Knowledge, Attitudes, and Behaviours towards Human Papillomavirus Vaccination for Their Children: A Systematic Review from 2001 to 2011. Obstet Gynecol Int. 2012;2012:921236.

37. Centers for Disease Control and Prevention (CDC). http://www.cdc.gov/ nchs/nis/data_files_teen.htm. Accessed 3 Feb 2017.

38. Jain N, Singleton JA, Montgomery M, Skalland B. Determining accurate vaccination coverage rates for adolescents: the National Immunization Survey-Teen 2006. Pub Health Rep. 2009;124:642-51.

39. Kahn JA, Ding L, Huang B, Zimet GD, Rosenthal SL, Frazier AL. Mothers' intention for their daughters and themselves to receive the human papillomavirus vaccine: a national study of nurses. Pediatrics. 2009;123(6):1439-45.

40. Dempsey AF, Abraham LM, Dalton V, Ruffin M. Understanding the reasons why mothers do or do not have their adolescent daughters vaccinated against human papillomavirus. Ann Epidemiol. 2009;19(8):531-8.

41. Warner EL, Lai D, Carbajal-Salisbury S, Garza L, Bodson J, Mooney K, Kepka D. Latino parents' perceptions of the HPV vaccine for sons and daughters. J Community Health. 2015;40(3):387-94.

42. Rand CM, Schaffer SJ, Humiston SG, et al. Patient-provider communication and human papillomavirus vaccine acceptance. Clin Pediatr (Phila). 2011; 50(2):106-13.

43. Dempsey AF, Zimet GD, Davis RL, Koutsky L. Factors that are associated with parental acceptance of human papillomavirus vaccines: a randomized intervention study of written information about HPV. Pediatrics. 2006; 117:1486-93.

44. Zimet GD, Mays RM, Winston Y, Kee R, Dickes J, Su L. Acceptability of human papillomavirus immunization. J Womens Health Gend-Based Med. 2000;9:47-50.

45. Davis K, Dickman ED, Ferris D, Dias JK. Human papillomavirus vaccine acceptability among parents of 10- to 15-year-old adolescents.J. Low. Genit. Tract Dis. 2004;8:188-94.

46. Marlow LA, Waller J, Wardle J. Trust and experience as predictors of HPV vaccine acceptance. Hum Vaccin. 2007:3:171-5.

47. Sperber NR, Brewer NT, Smith JS. Influence of parent characteristics and disease outcome framing on HPV vaccine acceptability among rural, Southern women. Cancer Causes Control. 2008;19(1):115-8.
48. Lai D, Ding Q, Bodson J, Warner EL, Kepka D. Factors Associated with Increased HPV Vaccine Use in Rural-Frontier US States. Public Health Nursing. 2015;33:283-94.

49. Kepka D, Ding Q, Bodson J, Warner EL, Mooney K. Latino Parents' Awareness and Receipt of the HPV Vaccine for Sons and Daughters in a State with Low Three-Dose Completion. J Cancer Educ. 2015;30(4):808-12.

\section{Submit your next manuscript to BioMed Central and we will help you at every step:}

- We accept pre-submission inquiries

- Our selector tool helps you to find the most relevant journal

- We provide round the clock customer support

- Convenient online submission

- Thorough peer review

- Inclusion in PubMed and all major indexing services

- Maximum visibility for your research

Submit your manuscript at www.biomedcentral.com/submit 